\title{
Design and Analysis of Small-scale Diffuser Augment Wind Turbines
}

\author{
Chen Yaqiong ${ }^{a}$, Fang Yuefa ${ }^{b}$ \\ School of Mechanical Electronic and Control Engineering, Beijing Jiaotong University, Beijing, \\ 100044, China
}

ajeromechen298@bjtu.edu.cn, ${ }^{\mathrm{b}}$ yffang@bjtu.edu.cn

Keywords: blade element momentum, Diffuser Augmented Wind Turbines, DAWT, wind energy utilization coefficient, wind turbines blade, power coefficient

\begin{abstract}
A new small-scale type diffuser augmented wind turbine (DAWT) is designed based on blade element momentum theory and the aerodynamic model of DAWT is established. This work presents an innovative approach to rotor blade design of small-scale diffuser augmented wind turbines. At the same radius and wind speed working conditions the new type DAWT has lower cut-in wind speed and the largest wind energy utilization coefficient of it is increased more than 1 times. Annual power generation of the new wind turbines is increased 2.34 times.
\end{abstract}

\section{Introduction}

As the key component of capturing the wind, the aerodynamic design parameter of wind turbine determines the power output of wind machine directly. Wind turbine performance is largely determined by the shape of airfoils. Jin Chen, Quan Wang ${ }^{[1]}$ et al. put forward to theory of the Trajkovski airfoil control parameters based on the curvature continuity, which was used to optimize the wind turbine airfoils, and dedicated wind turbine airfoil family with high performance was invented. Furthermore, other scholars ${ }^{[2] \sim 5]}$ optimize the parameters of wind turbine blades based on the optimization algorithm and evaluation indexes. The wind energy utilization coefficient will not exceed the Betz limit because the main configuration of the wind turbine does not change. The diffusion amplifier for small wind turbine is designed by Ravi Anant ${ }^{[6]}$ and that the diffusion amplifier can effectively improve the wind energy utilization coefficient of wind turbine is validated. SorenHjort $^{[7]}$, T.Y.Chen ${ }^{[8]}$ demonstrated that the diffusion amplifier had significant effect on enhancing the wind turbine aerodynamic character by experiments and CFD simulation of the diffuser wind machine. The new design method for the small-scale wind turbine is put forward based on the wind turbines blade element momentum theory of the diffusion amplifier in this paper, which reduces the start-up wind speed of wind turbine and improves the wind energy utilization coefficient of wind turbine.

\section{Computational Model Of Wind Farm And Anuual Power Generation}

The characteristics of the annual probability distribution of the wind energy is very important for the design of the wind turbine and the rated wind speed and the rated power of the wind turbine are all determined by the distribution characteristics of wind field. The mathematical model of wind speed is based on various measured typical wind speed frequency curves, which is built by the statistical probability method. The mathematic expression of the wind speed frequency curve, which is used to estimate the wind speed, is usually the Weibull function distribution ${ }^{[9]}$. The expression, which is a distribution function with single peak and two-parameters, is shown in formula (1).

$$
h_{w}(v)=\frac{k}{A}\left(\frac{v}{A}\right)^{k-1} \exp \left(-\left(\frac{v}{A}\right)^{k}\right)
$$

Where, $v$ is the wind speed; $k$ is shape parameter; $A$ is the scale parameter. From the weibull distribution, we can get the probability of the wind speed between $v_{i}$ and $v_{i+1}$ as :

$$
f\left(v_{i}<v<v_{i+1}\right)=\exp \left[-\left(\frac{v_{i}}{A}\right)^{k}\right]-\exp \left[-\left(\frac{v_{i+1}}{A}\right)^{k}\right]
$$


It needs to combine the power of the wind turbine with the probability density function of the wind field to evaluate the annual power generation of the wind turbine. The power generation the wind turbine is shown in formula (3):

$$
A E P=\sum_{i=1}^{N-1} \frac{1}{2}\left(P\left(V_{i+1}\right)+P\left(V_{i}\right)\right) \times f\left(\mathrm{~V}_{i}<\mathrm{V}<\mathrm{V}_{i+1}\right) \times 8760
$$

Where, AEP is the annual power generation; $P\left(V_{i+1}\right)$ is the power when the wind speed is $V_{i+1}$.

\section{Aerodynamic Shape Design Of Small-scale Diffuser-Augmented Wind Turbine}

The diffusion amplifier studied in this paper is two bending airfoils with opposing convex surfaces and the wind-velocity is enhanced when the airflow flows through the two airfoils ${ }^{[10]}$. Figure 1 shows the sketch map of airflow of the diffusion amplifier with built-in wind turbines.

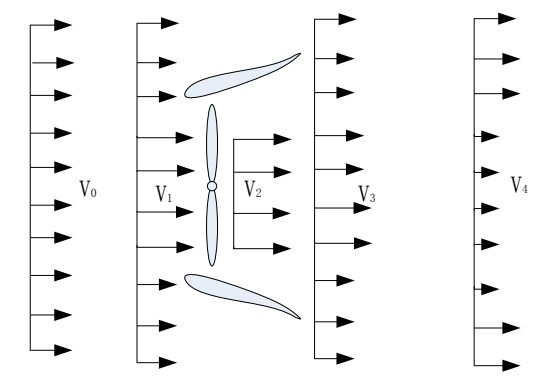

Fig.1 Sketch map of wind-velocity of airflow of DAWT

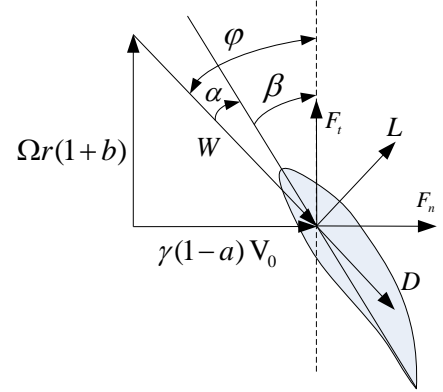

Fig.2 Force of the blade element

The speed-increasing ratio coefficient $\gamma$ of flow velocity of the diffusion amplifier is defined as follows:

$$
\gamma=\frac{V_{1}}{V_{0}}
$$

The velocity-inducing factor of wind turbine in axial direction is defined as $a$ and then the following formulas are deduced:

$$
\begin{aligned}
& V_{1}=\gamma V_{0}(1-a) \\
& V_{2}=V_{1} \\
& V_{4}=(1-2 a) V_{0}
\end{aligned}
$$

Where, $V_{0}$ is the wind velocity, $V_{1}$ is the wind velocity of diffusion amplifier.

The main design parameters include the choice of wind turbine airfoils, rotor diameter, chord length distribution and torsion angle distribution. The force of the blade element of the diffuser augmented wind turbine blade as well as the relative parameters is shown in Figure 2. The wind energy utilization coefficient is expressed by $C_{P}$ and the high wind energy utilization coefficient is the main design goal of the wind turbine blade. According to the blade element theory, the wind energy utilization coefficient of each blade element can be expressed as follows:

$$
d C_{p}=\frac{8}{\lambda_{0}^{2}} b(1-a) F \lambda^{3} d \lambda
$$

According to the momentum theory, the following formulas can be deduced:

$$
\begin{aligned}
& a(1-a F)=b(1+b) \lambda^{2} \\
& F=\frac{2}{\pi} \operatorname{arcos}(\exp (-f)) \\
& f=\frac{B}{2} \frac{R-r}{R \sin \varphi}
\end{aligned}
$$

Where, $a$ is the velocity-inducing factor in axial direction; $b$ is the velocity-inducing factor in circumferential direction; $F$ is the Prantl tip loss correction factor; $\lambda_{0}$ is the design blade tip-speed 
ratio; $B$ is the number of the blades; $R$ is the wind wheel radius; $r$ is the distance from the blade element to the central of the wind wheel; $\varphi$ is the inflow angle.

The wind energy utilization coefficient changes with the wind speed and the wind energy utilization coefficient can get a maximum value only in a tip-speed ratio. If the local wind energy utilization coefficient of each blade element reaches the maximum, then the entire wind turbine wind energy utilization coefficient is also the largest value. The ideal chord of wind turbine is shown in the formula (12) and the torsion angle distribution is given by the formula (14).

$$
\begin{aligned}
& C=\frac{8 \pi a F(1-a F)}{(1-a)^{2}} \frac{\sin ^{2} \varphi}{\cos \varphi} \frac{r}{B C_{L}} \\
& \varphi=a \tan \left(\frac{\gamma(1-a) V_{0}}{(1+b) \Omega r}\right) \\
& \beta=\varphi-\alpha
\end{aligned}
$$

Where, $C_{L}$ is the lift coefficient of the blade element; $\beta$ is the torsion angle of the blade element; $\alpha$ is the design angle of attack; $\Omega$ is the speed of the wind wheel.

\section{Aerodynamic Model Of Small-scale Diffuser Augmented Wind turbine}

The calculation of the aerodynamic performance of the wind turbine is an important part of the wind turbine blade design. The aerodynamic performance of the blade under different wind speeds is calculated after the designing the aerodynamic shape parameters of the blade and then the design results of the wind turbine can be evaluated ${ }^{[11][12]}$.

When the induction factor in axial direction is greater than 0.4 , the wind wheel works at the turbulent wake state and the momentum theory is no longer applicable at this moment and needs to be corrected. The correction expression of the inducing factor of the diffuser augmented wind turbine is deduced by Deborah ${ }^{[13]}$ based on the momentum theory of the traditional blade element. The correction expression is as follows:

$$
a= \begin{cases}\frac{1}{1+K} & a \leq a_{c} \\
0.5\left\{\begin{array}{l}
2+K\left(1-2 \mathrm{a}_{c}\right)- \\
\left.\sqrt{\left[K\left(1-2 \mathrm{a}_{c}\right)+2\right]^{2}+4\left(K \mathrm{a}_{c}^{2}-1\right)}\right\}
\end{array}\right. & a>a_{c}\end{cases}
$$

Where, $a_{c}=0.2$ is the critical point of the inducing factor in axial direction and according to the empirical model.

$K=\frac{4 F \sin ^{2} \varphi}{\gamma^{2} \sigma C_{n}}$

The axial force coefficient and the normal force coefficient are defined as follows:

$$
\begin{aligned}
& C_{n}=C_{L} \cos \phi+C_{D} \sin \phi \\
& C_{t}=C_{L} \sin \phi-C_{D} \cos \phi
\end{aligned}
$$

The velocity-inducing factor in circumferential direction is as follows:

$$
\begin{aligned}
& b=\frac{1}{1 / \mathrm{K}_{2}-1} \\
& K_{2}=\frac{\sigma C_{t}}{4 F \sin \varphi \cos \varphi} \\
& \sigma=\frac{B C}{2 \pi r}
\end{aligned}
$$

Where, $\sigma$ is the solidity of the blade.

The expression of the thrust and torque of wind turbine considering the tip loss of the blade is as follows:

$$
\begin{aligned}
& d q=4 \pi \rho V_{1}^{2} a F(1-a F) r d r \\
& d M=4 \pi \rho \Omega V_{1} b F(1-a F) r^{3} d r
\end{aligned}
$$

The thrust, torque and generated power of the ith blades are shown as follows:

$$
\begin{aligned}
T_{i} & =\int_{0}^{R} d q \\
Q_{i} & =\int_{0}^{R} d M \\
P_{i} & =Q \Omega
\end{aligned}
$$


The thrust coefficient of wind turbine and wind energy utilization coefficient are shown as follows:

$$
\begin{gathered}
C_{T}=\frac{\sum_{i=1}^{B} T_{i}}{\frac{1}{2} \rho \pi R^{2} V_{0}^{2}} \\
C_{P}=\frac{\sum_{i=1}^{B} P_{i}}{\frac{1}{2} \rho \pi R^{2} V_{0}^{3}}
\end{gathered}
$$

\section{Design Result And Discussion}

Under the action of diffusion amplifier, the velocity of the wind is increased when pass through the wind turbine, thereby enhancing the wind energy utilization coefficient. The wind speed field whose average wind speed is $6 \mathrm{~m} / \mathrm{s}$ and shape parameter $\mathrm{k}$ is 4.5 , is studied in this paper.

The chord length distribution whose radius of wind wheel is $6 \mathrm{~m}$ can be obtained from the formula(1). The WT01 wind turbine is defined in this paper. To illustrate the benefit in the structural parameter and aerodynamic performance of the diffuser-augmented wind turbine compared with the traditional wind turbine, the aerodynamics performance will be studied by using the traditional method to design that the wind wheel radius of the WT02 wind turbine is 6m and set the WT02 wind turbine under the diffusion amplifier.

Figure 3 shows the wind energy utilization coefficient of wind turbine in different tip-speed ratios. The WT01 wind turbine is designed based on the new working conditions of wind turbine blades, whose wind energy utilization coefficient can reach a maximum of 0.84 . However, the wind energy utilization coefficient of the WT02 wind turbine designed by traditional method can only reach a maximum of 0.46 without the diffusion amplifier and even if the WT02 wind turbine work with a diffusion amplifier, its wind energy utilization coefficient can only reach a maximum of 0.81 .

Figure 4 shows the output power distribution of wind turbine with different wind speeds in variable working conditions. The output power of the WT01 wind turbine blades is higher than the WT02 wind turbines' and it is obvious that the power of wind turbine with the function of the diffusion amplifier is larger than the traditional wind turbines'.

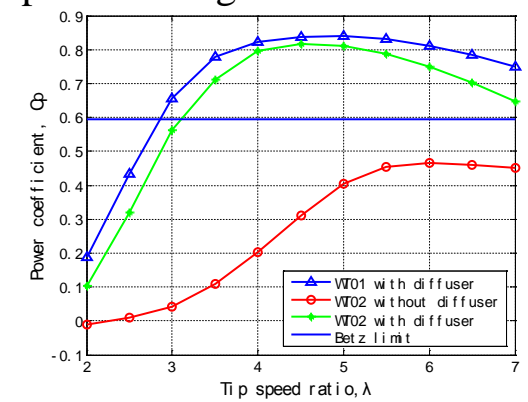

Fig.3 Power coefficient distribution

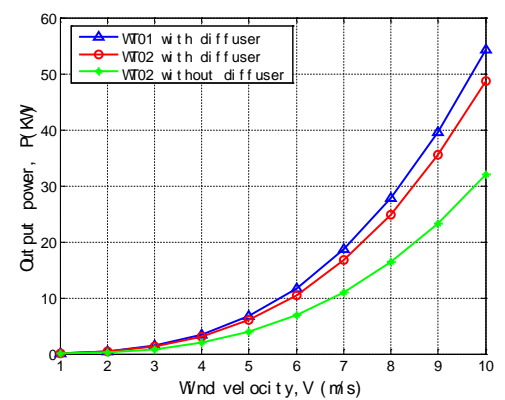

Fig.4 Output power distribution at variable speed

As is shown is Fig.5.a, in the three working conditions, the star-up wind velocity of the WT01 and WT02 wind turbine is $3.5 \mathrm{~m} / \mathrm{s}$ with the action of the diffusion amplifier, while the star-up wind velocity of the WT02 wind turbine is $4.8 \mathrm{~m} / \mathrm{s}$ without the action of the diffusion amplifier, therefore, the diffusion amplifier reduces the wind turbine star-up wind speed and improves the power generation. At rated wind speed is $8 \mathrm{~m} / \mathrm{s}$, the rated power of the WT01 wind turbine is $25.8 \mathrm{KW}$ and the WT02 wind turbine is $22.7 \mathrm{KW}$, for WT03 wind turbine is $13.4 \mathrm{KW}$. The annual power generation of wind turbine is shown in Fig.5.b, it is obvious that the rated power of the WT01 wind turbine running in working condition with the diffusion amplifier is significantly enhanced and its annual power generation increases to 2.03 times that of the traditional WT02 wind turbine. What's more, when the WT01 wind turbines run in the working condition with the diffusion amplifier and the traditional WT02 wind turbines run in the working condition with the diffusion amplifier, the annual power generation of the WT01 wind turbines increase 12.1\%. As is shown in Fig.5.c, the 
energy utilization coefficient is greatly increased for new type wind turbine with diffuser which is design by new method.

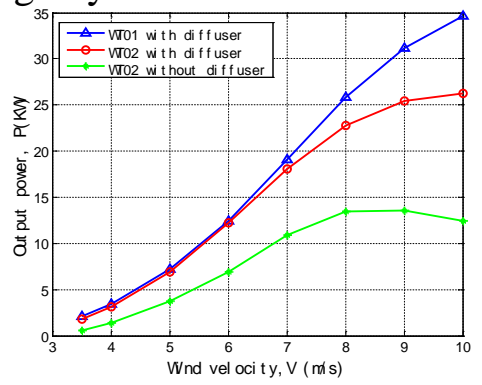

(a) Output power distribution

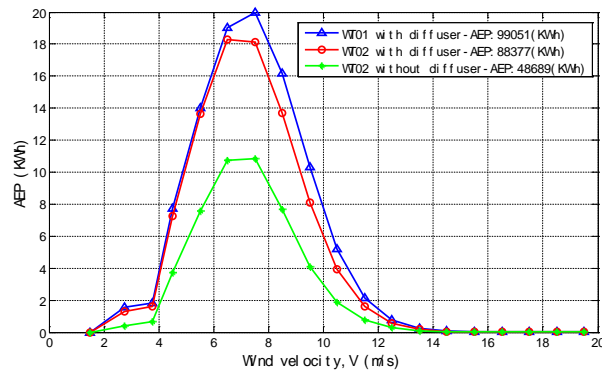

(b) Annual power generation distribution

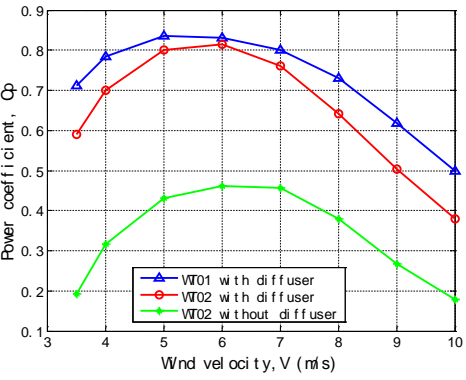

(c) Wind

energy utilization coefficient

Fig.5 Comparison of power characteristics of wind turbine in constant speed(6.5rad/s)

\section{Conclusion}

(1) The wind speed of wind turbine can be effectively improved by using the diffusion amplifier, therefore the star-up wind velocity of wind turbine is decreased, which makes full use of the wind energy resources.

(2) The wind energy efficiency of wind turbine is improved greatly by using the new diffuseraugmented wind turbines. With the action of the diffusion amplifier, the wind turbine works at a new working condition, therefore, the aerodynamic performance of wind turbine can be further increased by designing the structural parameters of shape again in the new working conditions.

\section{References}

[1] Jin Chen, Quan Wang. Improvement of airfoil design using smooth curvature technique. Renewable Energy, Vol.51:426-435 (2013)

[2] Kevin Maki, System design of a wind turbine using a multi-level optimization approach, Renewable Energy 43:101-110.(2012)

[3] Zhang Shiqiang. Multi-objective optimization of wind turbine airfoil profile based on genetic algorithm. acta energiae solaris sinica, Vol.32(8):1269-1274.(2011) [in Chinese]

[4] CHENG Jiangtao. Design of Wind Turbine Airfoils Based on Maximum Power Coefficient. Chinese Journal of Mechanical Engineering, Vol.46(24):111-117. (2010)[in Chinese]

[5] B. Bavanish. Optimization of power coefficient on a horizontal axis wind turbine using bem theory. Renewable and Sustainable Energy Reviews 26:169-182.(2013)

[6]Ravi Anant Kishore. Small-scale wind energy portable turbine(SWEPT). J. WindEng.Ind.Aerodyn., Vol.116:21-31. (2013)

[7] Søren Hjort. A Multi-Element Diffuser Augmented Wind Turbine. Energies,Vol.7: 32563281.(2014)

[8] T.Y. Chen. Development of small wind turbines for moving vehicles: Effects of flanged diffusers on rotor performance. Experimental Thermal and Fluid Science, Vol.42 :136-142.(2012)

[9] Chen Jin. wind turbine airfoils and theory of blade optimization design [M]. Science Press. Beijing, November.(2013)

[10] Qiyue Song. BEM Simulation and Performance Analysis of a Small Wind Turbine Rotor. WIND ENGINEERING. VOLUME 37, Vol.4:381-399.(2013) 
[11] Déborah. Optimum aerodynamic design for wind turbine blade with a Rankine vortex wake. Renewable Energy, Vol.55:296-304. (2013)

[12] V. Esfahanian. Numerical analysis of flow field around NREL Phase II wind turbine by a hybrid CFD/BEM method. J. Wind Eng. Ind. Aerodyn,Vol.120:29-36.(2013)

[13] Déborah. An extension of the Blade Element Momentum method applied to Diffuser Augmented Wind Turbines. Energy Conversion and Management (2014),in press. 